\title{
The Effects of Sea-Ice and Land-Snow Concentrations on Planetary Albedo from the Earth Radiation Budget Experiment
}

\author{
Irina V. Gorodetskaya ${ }^{* 1,2}$ Mark A. Cane ${ }^{1,2}$, L.-Bruno Tremblay ${ }^{1,2}$ and Alexey Kaplan ${ }^{1}$ \\ ${ }^{1}$ Lamont-Doherty Earth Observatory of Columbia University, Palisades, NY 10964, USA \\ ${ }^{2}$ Department of Earth and Environmental Science, Columbia University, USA.
}

[Original manuscript received 21 January 2005; in revised form 30 November 2005]

\begin{abstract}
The high-latitude ice/snow-albedo feedback is a principal element in many paleoclimate theories and global warming scenarios. The strength of this feedback is determined by the ice/snow effects on the top-of-atmosphere (TOA) albedo, which is also strongly affected by clouds. Using currently available satellite observations, we estimate the radiative effectiveness (RE) of ice and snow with regards to the TOA albedo, which we define as the change in the TOA albedo corresponding to changes of 0\% to 100\% in the ice or snow cover. The REs of the northern hemisphere $(\mathrm{NH})$ sea ice, land snow, and southern hemisphere (SH) sea ice are found to be 0.22, 0.23 and 0.16 , respectively. This means that, for an incident solar flux of about $400 \mathrm{~W} \mathrm{~m}^{-2}$ reaching the TOA in the polar latitudes in summer, local reduction in ice/snow concentrations from 100\% to $0 \%$ will result in a decrease in reflected short wave radiation of approximately $80 \mathrm{~W} \mathrm{~m}^{-2}$. These changes in the TOA albedo are significant, yet smaller than the associated changes in the surface albedo. Comparison of the TOA albedo values with available surface albedo observations helps to identify the role of clouds in the RE of ice/snow. The analysis is based on the whole time-space domain where the sea ice and land snow appear, and reveals a remarkable similarity in the ice and snow $R E$ in the areas with high sea-ice and land-snow cover variability, despite the varying nature of the surface cover, seasonality, and locations. These estimates provide a useful constraint to test current climate models.
\end{abstract}

RÉSUMÉ [Traduit par la rédaction] La rétroaction de l'albédo de la glace/neige dans les hautes latitudes est un élément principal dans plusieurs théories paléoclimatiques et scénarios de réchauffement de la planète. La force de cette rétroaction est déterminée par les effets de la glace/neige sur l'albédo du sommet de l'atmosphère, qui est aussi fortement influencé par les nuages. À l'aide des observations satellitaires présentement disponibles, nous estimons l'efficacité radiative de la glace et de la neige en relation avec l'albédo du sommet de l'atmosphère, efficacité définie comme le changement d'albédo au sommet de l'atmosphère correspondant à un changement de $0 \%$ à $100 \%$ dans la couverture de glace ou de neige. Nous trouvons que l'efficacité radiative de la glace de mer et de la neige au sol dans l'hémisphère Nord et de la glace de mer dans l'hémisphère Sud est de 0,22, 0,23 et 0,16, respectivement. Ceci signifie que pour un flux solaire incident d'environ $400 \mathrm{~W} \mathrm{~m}^{-2}$ au sommet de l'atmosphère dans les latitudes polaires en été, une réduction locale de la concentration de glace/neige de $100 \%$ à 0 \% entraînera une diminution du rayonnement de courtes longueurs d'onde réfléchi d'environ $80 \mathrm{~W} \mathrm{~m}^{-2}$. Ces changements dans l'albédo du sommet de l'atmosphère sont importants, bien qu'ils soient plus petits que les changements correspondants dans l'albédo de la surface. La comparaison des valeurs d'albédo du sommet de l'atmosphère avec les observations d'albédo de la surface disponibles aide à déterminer le rôle des nuages dans l'efficacité radiative de la glace/neige. L'analyse est basée sur tout le domaine temps-espace dans lequel il y a de la glace de mer et de la neige au sol et révèle une similitude remarquable dans l'efficacité radiative de la glace et de la neige dans les régions où la couverture de glace de mer et de neige au sol varie grandement, malgré la nature variée de la couverture de surface, de la saisonnalité et des endroits. Ces estimations fournissent une contrainte utile pour tester les modèles climatiques actuels.

\section{Introduction}

If the ice and snow cover expands, the Earth's albedo will increase, cooling the planet. The decreased temperature will allow the ice and snow cover to expand further - a positive feedback. This ice/snow-albedo feedback has long been at the core of simplified paleoclimate models (Budyko, 1969; Sellers, 1969; Gildor and Tziperman, 2000; Paillard, 2001) and is an important element in the early theories of Croll (1875) and Milankovitch (1941). General circulation model and theoretical studies have shown that the ice-albedo feedback is a principal climate feedback, enhancing the onset of the ice age driven by orbital forcing, as described by Milankovitch's theory (Khodri et al., 2005; Kukla and Gavin, 2003). Ice/snow-albedo feedback is also important for global warming scenarios (IPCC, 2001). Groisman et al. (1994) have proposed that the recent large increase in springtime surface air temperature over high latitude land areas of the northern hemisphere $(\mathrm{NH})$ is associated with the snow-albedo feedback.

It should be noted that the amplified surface warming (cooling) is also associated with other factors, in addition to

*Corresponding author's e-mail: irina@ ldeo.columbia.edu 
196 / Irina V. Gorodetskaya et al.

the ice/snow-albedo feedback. For example, in a double $\mathrm{CO}_{2}$ simulation by Hall (2004), the warming occurs mainly during the winter and fall and is related to an increased sensible heat flux through the thinner ice. However, the thinning of winter and fall ice is caused by increased absorption of solar radiation during summer and spring, which in turn is caused by a decrease in the surface albedo due to ice melt. Thus, the icealbedo feedback can trigger other feedbacks affecting surface temperatures both directly and indirectly.

The physics of the ice/snow albedo feedback are plausible and straightforward. The contrast between bright ice or snow and the darkness of the sea or land surface (especially if the latter is vegetated) is obviously strong. However, it is the topof-atmosphere (TOA) albedo that is the most important for cooling the planet, and other factors, such as clouds, might confound the simple relationship between ice/snow cover and TOA albedo. High latitudes are typically very cloudy, especially in maritime areas (e.g., Curry et al., 1996). One would expect cloud cover to increase greatly the TOA albedo over the open ocean, while making little difference over sea ice or snow.

Clouds are not the only feature that might interfere with a simple relationship between ice/snow cover and TOA albedo. Surface characteristics such as snow properties, ice thickness variations, presence of snow on top of sea ice, lead fraction, and melt pond characteristics will all influence albedo (Curry et al., 1995). By and large, these effects vary in the same manner with temperature as the ice/snow cover relationship. For example, warmer temperatures favour the creation of melt ponds, which reduce albedo. There are exceptions to this: very cold temperatures will reduce snowfall, and without freshly fallen snow, the albedo will decrease as the ice and snow surfaces age.

The radiative effectiveness $(R E)$ of snow or ice is defined as the change in TOA albedo for an ice/snow concentration change between $0 \%$ and $100 \%$ following Yamanouchi and Charlock (1997) (hereinafter YC97). It is diminished by the presence of clouds and altered by the ice/snow properties. The purpose of this paper is to quantify the $R E$ of sea ice and land snow from observational data, notably the TOA albedo values from the Earth Radiation Budget Experiment (ERBE). The ERBE dataset is known to have large uncertainties in identifying clear-sky scenes over ice surfaces ( $\mathrm{Li}$ and Leighton, 1991), precluding the use of the clear-sky datasets for the separation of the effects of sea ice and clouds on TOA albedo. Still, robust estimates of $R E$ were made here for all cloud conditions. These estimates can be used to calibrate simple climate models and to evaluate the strength of the ice/snow albedo feedback in general circulation models (GCMs).

Despite its deficiencies, the ERBE dataset has the longest continuous global record of the Earth's radiation. It has been applied to the study of the Earth's radiation budget, and used for model evaluation. Currently, new satellite data continuing the ERBE mission are becoming available through the National Aeronautics and Space Administration (NASA) Earth Observing System (Wielicki et al., 1995, 1996); these are derived using much improved algorithms, especially in the polar regions (see Kato and Loeb, 2005). The $R E$ estimates presented here provide the comparison baseline for future work with this new dataset.

There have been few prior studies of ice/snow $R E$ with respect to the TOA albedo. Seasonal and interannual variations in the $\mathrm{NH}$ land-snow cover and their impact on the radiative balance have been studied in detail by Groisman et al. (1994) using data from ERBE. Their analysis will not be repeated here. However, we do make snow cover $R E$ estimates in order to compare them with the sea-ice $R E$ values. The only previous estimates of the TOA broadband albedo sensitivity to sea-ice cover changes are available only for the Southern Ocean for the months of October 1987, January 1988 and April 1988 using ERBE data (YC97). Kuang and Yung (2000) and Lubin et al. (2003) presented results for the effects of ice and snow on the ultraviolet reflectance.

$\mathrm{Qu}$ and Hall (2005) studied the contributions from the atmosphere and the surface to planetary albedo for various regions of the world, using data from the International Satellite Cloud Climatology Project (ISCCP). The radiative fluxes in the ISCCP dataset were calculated using a radiative transfer model with specified clouds from the ISCCP, sea-ice and snow cover data, and the vertical profiles of the atmospheric temperature, humidity, gases and aerosols. Qu and Hall (2005) found that, although clouds significantly diminish the surface contribution to the TOA albedo in the polar regions, the variability of the TOA albedo is still controlled by the surface albedo. Wang et al. (2004) proposed a parametrization of the planetary albedo and solar energy disposition in the atmosphere for climate models. While their calculated solar energy disposition was in agreement with observations over most of the world, they emphasize the biases in both data and simulations found in the polar regions. In the present study, independent datasets are used to explore the relationship between the ice/snow cover and the TOA albedo.

The paper is structured as follows. Section 2 describes the data. Section 3 presents the methodology and the results. The conclusions and discussion are provided in Section 4.

\section{Data}

\section{a TOA Albedo}

The ERBE is a multi-satellite system designed to measure the Earth's radiation budget. The ERBE instruments flew on a midinclination NASA satellite (Earth Radiation Budget Satellite (ERBS)) and two sun-synchronous National Oceanic and Atmospheric Administration (NOAA) satellites (NOAA-9 and NOAA-10). The ERBS has a latitudinal coverage between $67.5^{\circ} \mathrm{N}$ and $67.5^{\circ} \mathrm{S}$, and the polar-orbiting NOAA satellites have global coverage (Barkstrom et al., 1989; Barkstrom and Smith, 1986). The ERBS data are available from November 1984 to February 1990 (64 months). The data from the NOAA-9 and/or NOAA-10 satellites are available from February 1985 to May 1989 (52 months). In the ERBE dataset, the observed radiances are converted to monthly TOA fluxes using scene-dependent angular models and averaging over time and space (Barkstrom et 


\section{Ice and Snow Effects on Planetary Albedo / 197}

al., 1989). We use spectrally integrated (over the 0.2-5.0 $\mu \mathrm{m}$ band) monthly total-sky TOA albedo values from the ERBE dataset with a spatial resolution of $2.5^{\circ} \times 2.5^{\circ}$ (http://charm.larc.nasa.gov/GUIDE/dataset_documents/erbe_s4 g.html).

Wielicki et al. (1995) report a global error of $5.5 \mathrm{~W} \mathrm{~m}^{-2}$ (or $1.6 \%$ of the incoming flux of $348 \mathrm{~W} \mathrm{~m}^{-2}$ ) for ERBE monthly short wave (SW) radiation values. In the polar regions, the errors are higher for a number of reasons. Firstly, ERBE has limitations in defining clear-sky and cloudy scenes over ice/snow surfaces (Li and Leighton, 1991). Secondly, using a fixed climatological snow/ice boundary gives inaccurate seaice extent during some months (Li and Leighton, 1991; Smith and Manalo-Smith, 1995). Thirdly, using a non-varying ice/snow albedo equal to the value for winter fresh snow $(\mathrm{Li}$, 1996; Wielicki and Greene, 1989) is inaccurate. Li and Leighton (1991) compared SW radiation fluxes for a period of four days in July 1985 using scene identification from both ERBE and the Advanced Very High Resolution Radiometer (AVHRR). Both instruments flew on the NOAA-9 platform; the latter allows a more reliable cloud identification. They showed good agreement between zonal mean total-sky fluxes, but large differences for clear-sky conditions (up to $50 \mathrm{~W} \mathrm{~m}^{-2}$ ). These uncertainties in clear-sky identification over ice surfaces make separate analyses of the data for clearsky conditions and cloudy-sky conditions unreliable. Hence, only total-sky analyses are presented here.

Sampling during specific times of the day can produce biases in the diurnal average values, largely due to the diurnal cycle in cloud cover. Duvel et al. (2000) analysed these biases by comparing the SW flux estimates in the Southern Ocean during December 1986 derived from the NOAA-9 satellite to those derived from combining data from the three satellites (ERBS, NOAA-9 and -10 ), which provide a higher accuracy product. The differences between the retrievals from the single satellite and from the combination of satellites were, on average, from -3 to $3 \mathrm{~W} \mathrm{~m}^{-2}$, reaching $10 \mathrm{~W} \mathrm{~m}^{-2}$ in certain regions. Given the incoming SW flux of approximately $450 \mathrm{~W} \mathrm{~m}^{-2}$ during the summer at polar latitudes, the difference in albedo is about $\pm 0.7 \%$, reaching 2\% in certain regions. Rieland and Raschke (1991) demonstrated the possible errors due to the temporal integration biases by comparing the ERBE (from the ERBS and two NOAA satellites) and Meteosat (a geostationary satellite) fluxes derived using ERBE time integration techniques in April 1985. They found large differences in the monthly mean net radiation flux over mid-latitude oceans for the ERBS and NOAA satellites (up to $19 \mathrm{~W} \mathrm{~m}^{-2}$ and $15 \mathrm{~W} \mathrm{~m}^{-2}$, respectively, or $6 \%$ and $5 \%$ for an incoming flux of $\sim 300 \mathrm{~W} \mathrm{~m}^{-2}$ during spring at polar latitudes). They attributed these biases to the diurnal cloud cycle, and found that combining data from the two or three satellites decreases the uncertainty (the ERBE dataset is based on the data from at least two satellites from February 1985 to May 1989).

To summarize, the estimated errors for the TOA albedo are $1.6 \%$ for the global average, possibly reaching $6 \%$ in certain regions at polar latitudes. These errors contribute to the scatter of the TOA albedo but are substantially smaller than the changes in TOA albedo associated with seasonal variations in sea-ice and land-snow concentrations (up to 20\%).

\section{b Sea-Ice and Land-Snow Concentrations}

The ice or snow concentration in a grid box is characterized by the monthly averages of the snow- or ice-covered area of a grid box as a percentage of its entire area. These gridded values are obtained by averaging the datasets of sea-ice concentration (SIC) and snow cover onto the $2.5^{\circ} \times 2.5^{\circ}$ monthly grid used in the ERBE dataset.

The SICs are taken from the UK Met Office Hadley Centre's sea-ice and sea surface temperature (SST) dataset, HadISST1 (Rayner et al., 2003). The HadISST1 dataset replaces the Global sea Ice and Sea Surface Temperature (GISST) datasets, and is a unique combination of monthly globally complete fields of SST and SIC on a 1 degree latitude-longitude grid from 1870 to the current time (http://hadobs.metoffice.com/hadisst/index.html) produced using information from ground-based and satellite observations. We are using the satellite era part of the HadISST1 dataset, in which the SIC data are derived from the Special Sensor Microwave/Imager and the Scanning Multichannel Microwave Radiometer data using the Team algorithm (Gloersen et al., 1992). The estimated error in monthly averaged SIC derived from microwave radiances using the Team algorithm is about $7 \%$, increasing up to $11 \%$ during the melt season (Gloersen et al., 1992). Cloud liquid water and atmospheric water vapour lead to the overestimation of the firstyear ice concentrations, and underestimation of the multiyear ice concentrations, derived from the microwave satellite observations (Oelke, 1997). Melting of snow on top of sea ice and ice ponding can mask the presence of ice in microwave signatures and cause underestimation of the SICs (http://nsidc. org/data/docs/daac/nasateam/). The biases are greatly reduced in the homogenization process used in the production of the HadISST1 dataset: special corrections were applied using other satellite and in situ SIC and extent data, including corrections for the effects of surface melt water and wet snow on the passive microwave sensor signals (Rayner et al., 2003).

The NH snow cover data were obtained from the National Snow and Ice Data Center (NSIDC) Weekly Snow Cover and Sea Ice Extent dataset (http://nsidc.org/data/nsidc-0046.html). The snow cover data are based on the NOAA-NSIDC weekly snow charts, revised by Robinson using the Rutgers routine (Robinson et al., 1993). The original dataset contained information about the presence (1) or absence (0) of snow in a given week for each grid cell of the $25-\mathrm{km}$ equal-area grid derived from manual interpretations of NOAA satellite visible images (Armstrong and Brodzik, 2001; Matson and Wiesnet, 1981; Robinson et al., 1993). Snow was considered present (1) only if the cell is at least 50\% snow covered (Robinson et al., 1993). We averaged the weekly snow presence information for each month and linearly interpolated the data from the equal-area grid onto the ERBE $2.5^{\circ} \times 2.5^{\circ}$ grid. As a result of averaging, we obtain snow concentrations from the original data on the snow presence. Although NOAA satellite data are known to be less accurate in areas with persistent cloud cover and/or heavy 
(a)

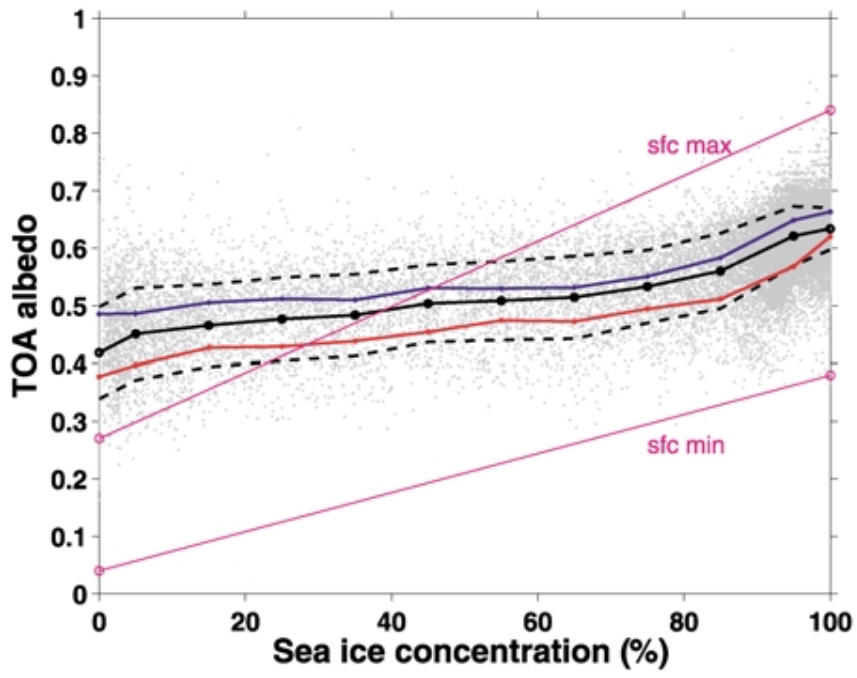

(b)

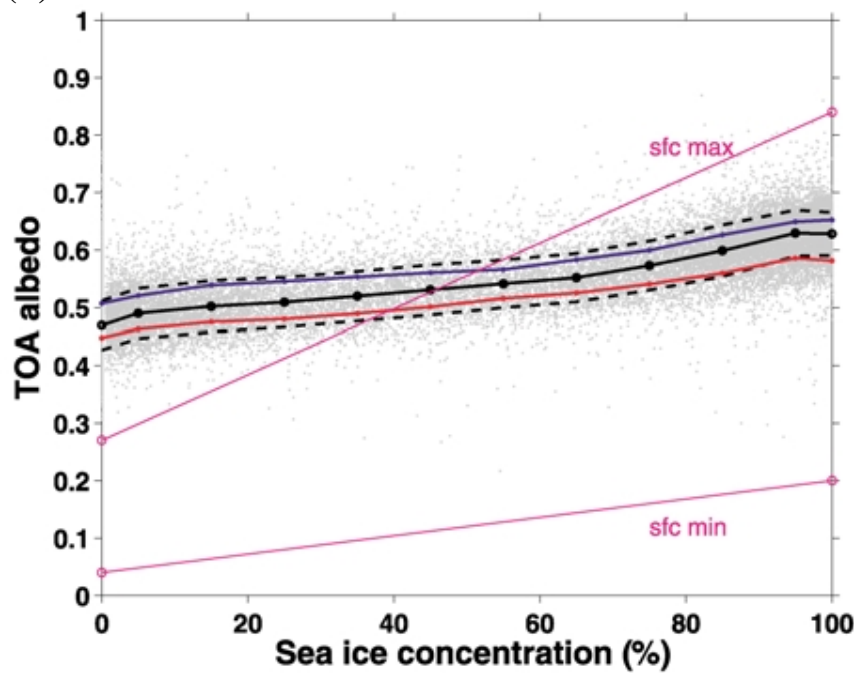

(c)

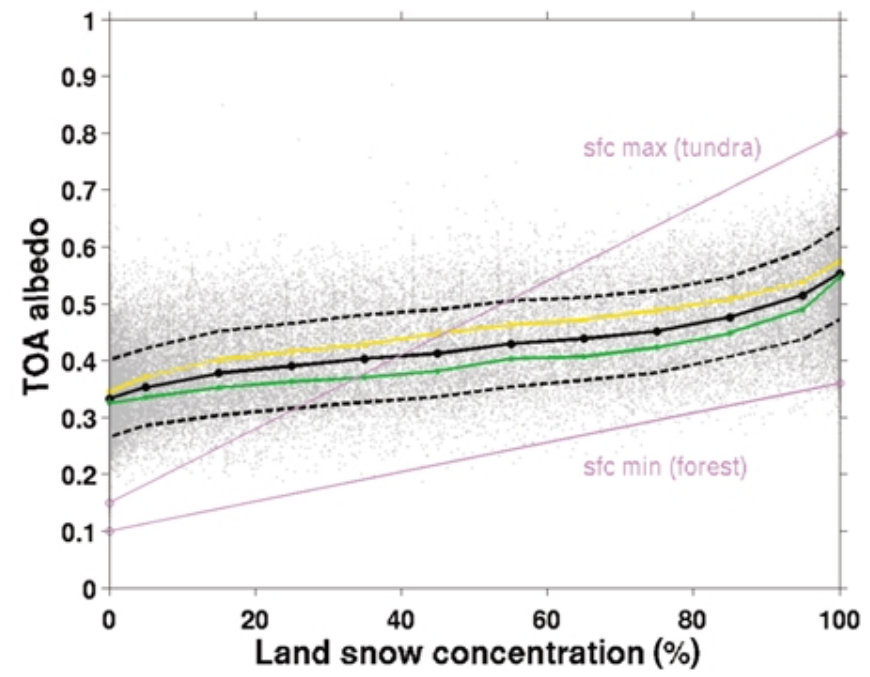

Fig. 1 Monthly mean TOA albedo (grey dots) against sea-ice concentrations (SIC) and land-snow concentrations (SC): (a) NH sea ice, (b) SH sea ice, and (c) NH land snow. Included are data for all grid boxes where ice or snow was present for at least one month during the ERBE time period (64 months equatorward and 52 months poleward of the polar circles, including at least 30 sunlit months poleward of the polar circles). Area-weighted TOA albedo averages for $0 \%$, $100 \%$, and each 10\% bin of SIC/SC for all data (black dots), and for the seasons with extreme TOA albedo in each case. Winter (blue) is December-February in the NH and June-August in the SH, summer (red) is June-August in the NH and December-February in the SH); fall (yellow) and spring (green) are September-November and March-May respectively. The standard deviations for all data are shown as dashed lines. Thin magenta lines connect maximum and minimum surface albedo values for the open ocean and sea ice, and for tundra and forest over land (sources cited in text).

forest (Scialdone and Robock, 1987; Wiesnet et al., 1987), they are the longest available consistent records of large-scale variations in snow cover, and their accuracy was found to be adequate for climate-related studies at the continental scale (Wiesnet et al., 1987).

\section{Results}

a TOA and Surface Albedo Versus Ice/Snow Concentrations Figure 1 shows the monthly TOA albedo plotted against seaice and land-snow concentrations for every grid box where ice/snow concentrations were non-zero during at least one month of the ERBE time period (November 1984-February 1990). The area-weighted mean TOA albedo, corresponding to values of $0 \%, 100 \%$, and all $10 \%$ bins of ice/snow concentrations are shown along with standard deviations of these subsamples. Two methods were used to estimate the $R E$ of the ice/snow cover with regards to the TOA albedo. The first approach computes $R E=$ albedo $(100 \%$ ice/snow concentration) - albedo ( $0 \%$ ice/snow concentration). The second approach follows YC97 and Groisman et al. (1994) and is 


\section{Ice and Snow Effects on Planetary Albedo / 199}

based on the linear regression: albedo $=R E * C+B$, where $C$ is the ice/snow concentration, and $B$ is the regression intercept. In this case $R E$ is determined using the regression slope. The two methods give very similar estimates for $R E$ (see Table 1). The $R E$ of the NH sea ice, land snow, and southern hemisphere $(\mathrm{SH})$ sea ice are found to be $0.22,0.23$, and 0.16 , respectively.

The scatter in the TOA albedo values over each SIC bin (Fig. 1) is due to a variety of factors: effects of ice/snow properties, cloud cover, solar zenith angle, and errors in satellite data. The errors in the ice/snow concentration and albedo data are substantially smaller than the changes in TOA albedo associated with seasonal variations in sea-ice and land-snow concentrations (up to 20\%). Persistent low clouds, typical for the polar regions, significantly diminish the surface albedo dependence on the solar zenith angle as they decrease the amount of direct solar flux reaching the surface (Curry and Webster, 1999). Here we present the comparison of TOA albedo values with available surface albedo observations (as a function of the solar zenith angle for the open ocean, vegetation for the land surface, and the ice/snow properties) to identify the role of clouds in the $R E$ of ice/snow.

The surface albedo of Arctic ice can be as low as 0.38 during the melt season and as high as 0.84 for ice covered with dry snow (Curry et al., 2001). The surface albedo of the Southern Ocean sea ice varies from about 0.2 to 0.84 depending on the ice type and snow cover (Allison et al., 1993). The open ocean surface albedo can increase from 0.03 for low solar zenith angles to 0.27 for high solar zenith angles (Curry and Webster, 1999). These surface albedo values define an envelope of the surface albedo ranges shown by the magenta lines in Figs 1a and 1b: the upper line represents winter/fall/spring surface albedo, and the lower line represents the melt season.

Over land, vegetation has a substantial effect on surface albedo, reducing the impact of snow cover on the TOA albedo. Liou (1992, Table 6.4) found surface albedo values of $\sim 0.15$ for summer tundra and $\sim 0.1$ for boreal forest. In winter, surface albedo can range from 0.8 over the snow-covered polar tundra to 0.36 over boreal forest (Robinson and Kukla, 1985). In Fig. 1c the magenta lines connect the summer (snow free) and winter (snow covered) values of surface albedo over tundra (upper line) and over boreal forest (lower line).

In all three panels of Fig. 1 the observed values of the TOA albedo are above the range of the surface albedo at low ice/snow concentrations and within the surface albedo range at high ice/snow concentrations. This demonstrates the important role of non-surface effects; i.e., the atmosphere and clouds, in reducing the effects of the ice/snow surface cover on TOA albedo values. While the solar zenith angle causes a significant change in the open ocean surface albedo and vegetation greatly changes the land surface albedo, the effects of clouds overwhelm these changes and increase the mean TOA albedo over the open ocean/land above the maximum observed ice-snow/free surface albedo. In contrast, over areas with $100 \%$ ice/snow concentrations the combination of the
TABLE 1 Area-weighted averages (mean) of the TOA albedo and standard deviations (std) corresponding to $0 \%$ and $100 \%$ of seaice or land-snow concentrations (SIC or SC, respectively). Radiative effectiveness $(R E)$ of ice/snow was computed both as the difference between the mean TOA albedo for the $100 \%$ and $0 \%$ of $\operatorname{SIC/SC}(\Delta)$ and using linear regression (LR). Correlation coefficients $(r)$ between SIC/SC and TOA albedo for all monthly data are listed in the last column.

\begin{tabular}{|c|c|c|c|c|c|c|c|}
\hline \multirow{3}{*}{ SIC or SC } & \multicolumn{4}{|c|}{ TOA albedo } & \multicolumn{2}{|c|}{$R E$} & \multirow[t]{3}{*}{$r$} \\
\hline & \multicolumn{2}{|c|}{$0 \%$} & \multicolumn{2}{|c|}{$100 \%$} & $\Delta$ & LR & \\
\hline & mean & std & mean & std & & & \\
\hline $\mathrm{NH}$ sea ice & 0.42 & 0.08 & 0.63 & 0.04 & 0.21 & 0.21 & 0.81 \\
\hline SH sea ice & 0.47 & 0.04 & 0.63 & 0.04 & 0.16 & 0.15 & 0.82 \\
\hline $\mathrm{NH}$ land snow & 0.33 & 0.07 & 0.55 & 0.08 & 0.22 & 0.22 & 0.77 \\
\hline
\end{tabular}

effects of the surface and clouds results in the mean TOA albedo lying within the extreme surface albedo values. The mean TOA albedo over the ice/snow cover is based on the monthly values not only for different cloud conditions but also for various ice/snow properties ranging from low albedo values over ponded ice (or evergreen forest for the land snow) to very high albedo values over fresh snow. The ability of clouds to increase the TOA albedo even over the permanent snow compared to the surface albedo (e.g., Kato and Loeb, 2005) has a smaller effect on the TOA albedo than the variations in the ice/snow properties.

\section{b Seasonal Variability of the Ice/Snow RE}

Because ice, snow, and cloud properties change during the year, ice/snow $R E$ is expected to have seasonal variability. Seasonal changes in the mean TOA albedo occur over all ice/snow concentrations, causing small variations in the $R E$ (Fig. 1). These TOA albedo changes are due to the changes in the cloud and surface properties, and in the solar elevation angle. Figures $1 \mathrm{a}$ and $1 \mathrm{~b}$ show winter and summer TOA albedo values (blue and red curves) when the mean TOA albedo is the highest and the lowest, respectively, over both the open ocean and all SICs. In the cold season, the TOA albedo over the open ocean is high due to low solar angles and likely also due to frequent fog and convective cloud formation over the warmer ocean surface (Klein and Hartmann, 1993). Fresh snow increases the reflectance of sea ice, affecting the TOA albedo over the ice-covered and sunlit areas. In summer, ponded sea ice has a lower surface albedo, decreasing the TOA albedo over areas with $100 \%$ SICs, while larger solar angles decrease the open ocean albedo. At the same time, higher storm activity in the Arctic increases cloudiness over both the perennial sea ice of the central Arctic and the open ocean. However, the increased cloudiness is not sufficient to reverse the surface influence on the TOA albedo, which is lowest in summer at all SICs (Fig. 1).

The highest (lowest) mean TOA albedo values over the $\mathrm{NH}$ land were found in the fall (spring) regardless of the snow concentrations (Fig. 1c, yellow and green curves). The high fall TOA albedo values over the NH land for any snow 
concentration are probably related to the more frequent occurrence of fresh snow on the ground, while high albedo over snow-free ground could be related to the increased temperature gradient and thus increased frequency and intensity of cyclones associated with more clouds. In spring the snow albedo is decreased due to warmer temperatures (see Groisman et al., 1994). In summer, the $R E$ of snow is not important since there are very few locations in the north with snow on the ground.

Table 2 shows seasonal and monthly variations of the $R E$ based on spatial changes of the ice/snow concentrations and the TOA albedo. The $R E$ is calculated as the linear regression coefficient. Within each season, there is monthly variation of $R E$. However, when the $R E$ is computed for the whole season, the monthly variations are smoothed out (Table 2). Spring $R E$ is highest for both $\mathrm{NH}$ and $\mathrm{SH}$ ice, and for land snow, though the difference between the spring $R E$ and the $R E$ for other seasons is only significant for the $\mathrm{SH}$ sea ice. The smaller sea-ice $R E$ during winter months (November-January in the $\mathrm{NH}$, and May-June in the $\mathrm{SH}$ ) is due to the smaller proportion of the icecovered area that is sunlit (mostly near the ice edge) compared to the rest of the year. This reduces the effect of the ice on the TOA albedo, while the TOA albedo over the open ocean is very high. The weaker correlations between SIC and TOA albedo during winter months are also caused by larger errors in satellite ice retrievals near the ice edge. These errors, to a large extent, are due to more frequent cloudiness accompanying the ocean-ice transition and lower sun angles in winter. These months are indicated by asterisks in Table 2. Smaller correlation coefficients compared to the rest of the year are also found between land-snow concentrations and the TOA albedo during July--August, when the snow on land has almost completely melted (marked with asterisks in Table 2). For each season except summer the land-snow $R E$ is equal or close to the overall $R E$ based on the whole time-space domain (0.22).

Our estimates of the $\mathrm{SH}$ sea-ice $R E$ for October, January, and April (0.18,0.13, and 0.14, respectively) obtained by linear regression for all years in the ERBE period, are close to the YC97 estimates for October 1987, January 1988 and April $1988(0.19,0.13$, and 0.12 , respectively). The latter estimates were calculated from Table 1 of YC97 as area weighted averages of zonal values excluding the lowest latitude values for January and October, which YC97 considered to be an artefact. Comparing the area averaged values is suitable since there are only small variations of $\mathrm{SH}$ ice $R E$ with latitude as noted by YC97 (and consistent with our results). We found that summer $R E$ values are similar to the fall and winter values, while austral spring $R E$ is the highest (Table 2) consistent with the YC97 findings based only on three months. Our results based on the longer time series showed that seasonally averaged $\mathrm{SH}$ ice $R E$ have only small variations for most of the year, values in spring being slightly larger. Although ice $R E$ is maximum in spring in both hemispheres, both the pattern and the amplitude of the seasonal $R E$ changes are different. During all seasons, the ice $R E$ is higher in the $\mathrm{NH}$ compared to the $\mathrm{SH}$. Summer and fall ice $R E$ in the $\mathrm{NH}$ is
TABLE 2. Radiative effectiveness $(R E)$ of the NH sea ice and land snow and SH sea ice based on linear regression for each month and season (seasonal $R E$ is calculated using the data from all corresponding months and is in bold font). Asterisks denote the months when a large fraction of the sea-ice area is not sunlit or when land snow covers only small areas. For all these cases the correlations between the TOA albedo and ice/snow correlations are reduced compared to the rest of the year but still significant.

\begin{tabular}{lllc}
\hline Time & NH ice & SH ice & Snow \\
\hline Dec & $0.10^{*}$ & 0.14 & 0.15 \\
Jan & $0.13^{*}$ & 0.13 & 0.22 \\
Feb & 0.18 & 0.15 & 0.20 \\
DJF & $\mathbf{0 . 1 6}$ & $\mathbf{0 . 1 3}$ & $\mathbf{0 . 1 9}$ \\
Mar & 0.19 & 0.13 & \\
Apr & 0.23 & 0.14 & 0.19 \\
May & 0.25 & $0.11^{*}$ & 0.22 \\
MAM & $\mathbf{0 . 2 2}$ & $\mathbf{0 . 1 3}$ & 0.24 \\
Jun & & & $\mathbf{0 . 2 2}$ \\
Jul & 0.23 & $0.10^{*}$ & \\
Aug & 0.17 & 0.14 & 0.18 \\
JJA & 0.20 & 0.15 & $0.14^{*}$ \\
Sep & $\mathbf{0 . 2 0}$ & $\mathbf{0 . 1 4}$ & $0.20^{*}$ \\
Oct & 0.20 & 0.18 & $\mathbf{0 . 1 6}$ \\
Nov & 0.20 & 0.18 & 0.25 \\
SON & $0.15^{*}$ & 0.16 & 0.24 \\
\hline
\end{tabular}

close to the spring maximum in contrast to the $\mathrm{SH}$ where the spring maximum stands alone.

The $R E$ of the NH land snow based on the whole timespace domain $(0.22$, Table 1$)$ is in agreement with the $R E$ estimates obtained by Groisman et al. (1994, Fig. 9) for the coldest temperatures they considered $\left(-8^{\circ}\right.$ to $\left.-14^{\circ} \mathrm{C}\right)$. Their $R E$ estimates for warmer temperatures are smaller (decreasing to 0.05 as surface air temperature increases to $0^{\circ} \mathrm{C}$ ).

\section{c Spatial Variability of the Ice/Snow RE}

The following results are based on Fig. 2 showing the ice/snow $R E$ for each grid box. The $R E$ is calculated as the linear regression coefficient at all locations where the correlation coefficient between the ice/snow concentrations and TOA albedo is significant at the $99 \%$ level. The spatial distribution of the ice/snow RE (Fig. 2) depends on the seasonal variability of the ice/snow concentrations (Fig. 3). The TOA albedo seasonal variability is small and almost uniform with standard deviations ranging from 0.05 to 0.1 for most locations where sea ice or land snow appears and the correlation coefficient between the ice/snow concentrations and the TOA albedo is statistically significant (Fig. 4).

We may classify the spatial patterns of $R E$ into three types. Type I is characterized by the $R E$ values close to the overall $R E$ estimates based on the whole time-space domain (Fig. 1, Table 1) and correlation coefficients above 0.8 . Type I conditions are found in the peripheral seas in the $\mathrm{NH}$, and in almost the entire Southern Ocean and NH land area (Fig. 2). These regions have high seasonal variability of the ice/snow 
(a)

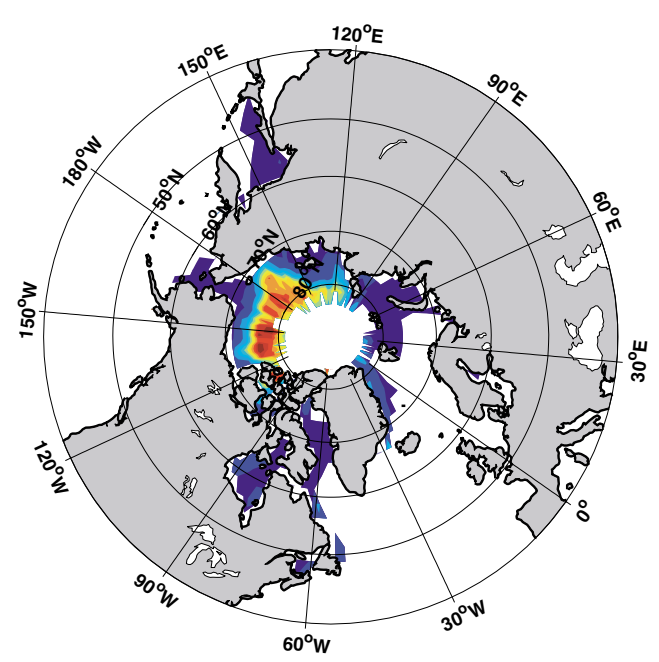

(b)

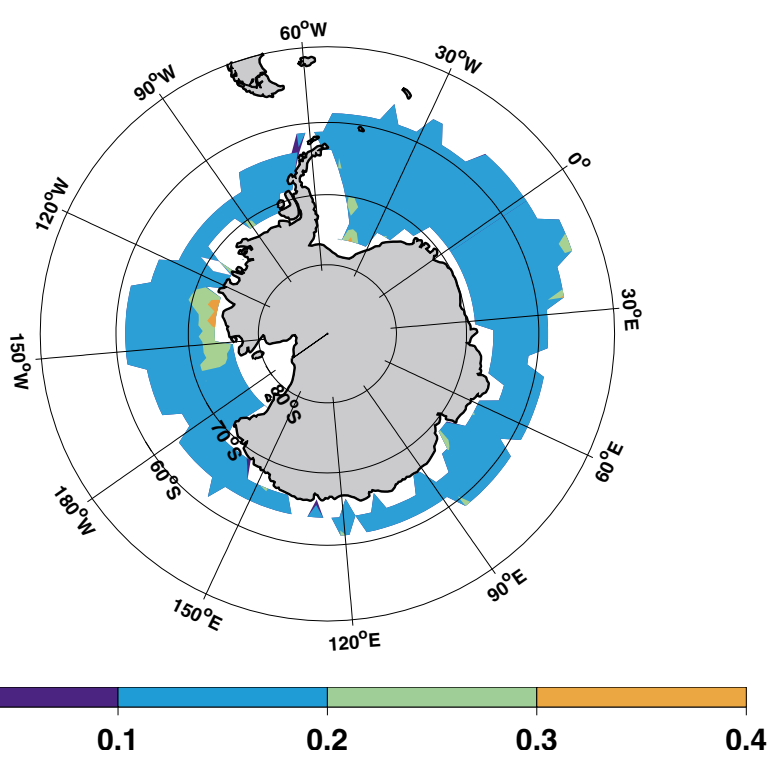

(c)

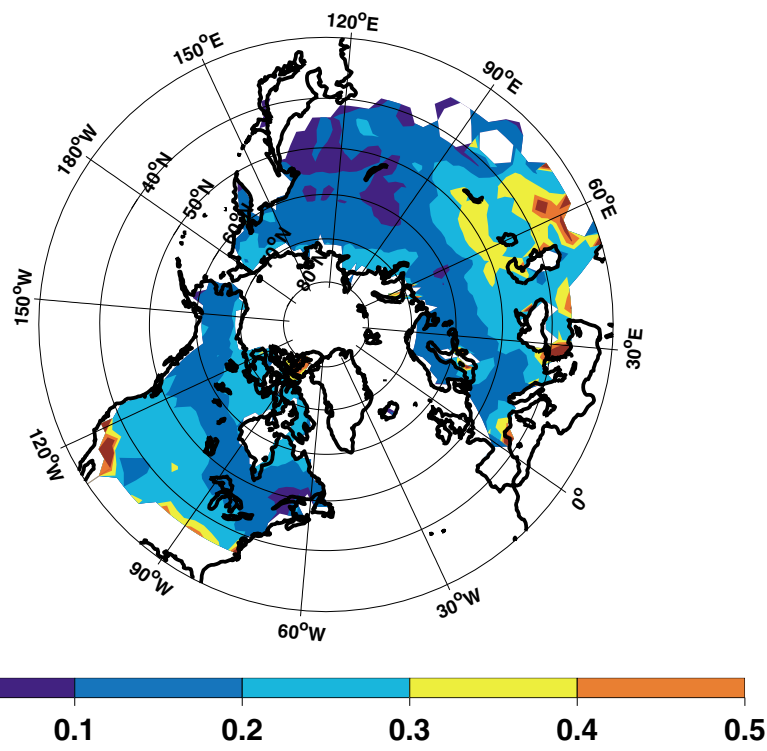

Fig. 2 The spatial distribution of the radiative effectiveness $(R E)$ based on linear regression between monthly values of the TOA albedo and ice/snow concentrations for (a) NH sea ice, (b) SH sea ice, and (c) NH land snow. Only the locations with correlation coefficients significant at the 99\% level are plotted. The $R E$ at each grid box is based on time series 64 months long (November 1984-February 1990) equatorward of the polar circles, and at least 30 months long poleward of the polar circles for only the sunlit grid boxes up to 52 months long when the data from the NOAA-9 and/or NOAA10 satellites are available (February 1985-May 1989).

concentrations (from $0 \%$ to $100 \%$ at most locations) and high frontal activity, so abundant clouds decrease the effects of ice on the TOA albedo (Serreze et al., 1993, 2001). The TOA albedo changes are small but robust (Figs 1 and 4). This type also includes the areas with slightly higher than average ice/snow REs in the southern regions for land snow and in the Amundsen Sea (Figs. 2b and 2c).

Type II regions have very high $R E$ values resulting from very small variability of the ice/snow concentrations and small but robust changes in the TOA albedo similar to Type I. Local correlation coefficients between them are about 0.5 and statistically significant. Type II conditions occur only in the perennial sea-ice region in the central Arctic (Fig. 2) where SIC varies, for the most part, between $80 \%$ and $100 \%$, while TOA albedo varies between 0.5 and 0.7 . Thus, while the SIC seasonal variability is much smaller compared to the Type I regions (Fig. 3a), the TOA albedo seasonal variability is comparable (Fig. 4a). Figure 1a shows a significant increase in the TOA albedo over SICs higher than $80 \%$.

Type III regions also have very small seasonal variability of the ice/snow concentrations, which have no statistically significant correlations with the TOA albedo. The regions described by the Type III conditions are left white on Fig. 2. These regions include the middle of the central Arctic, 
(a)

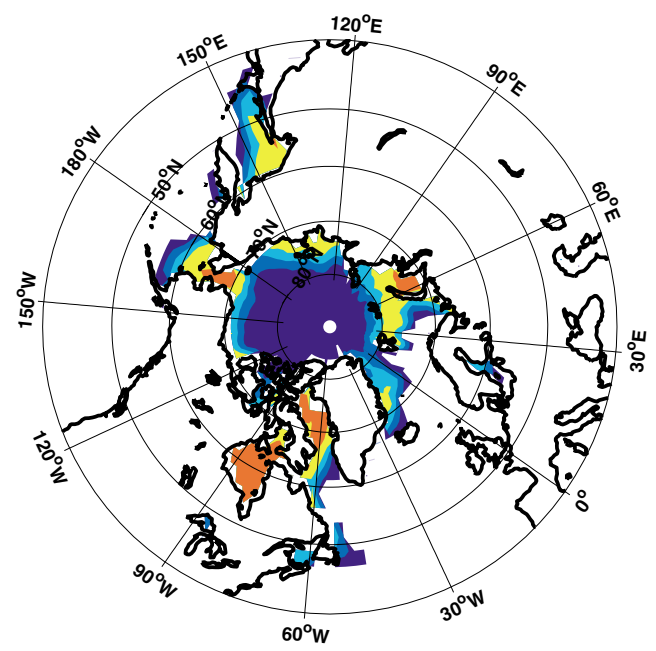

(b)

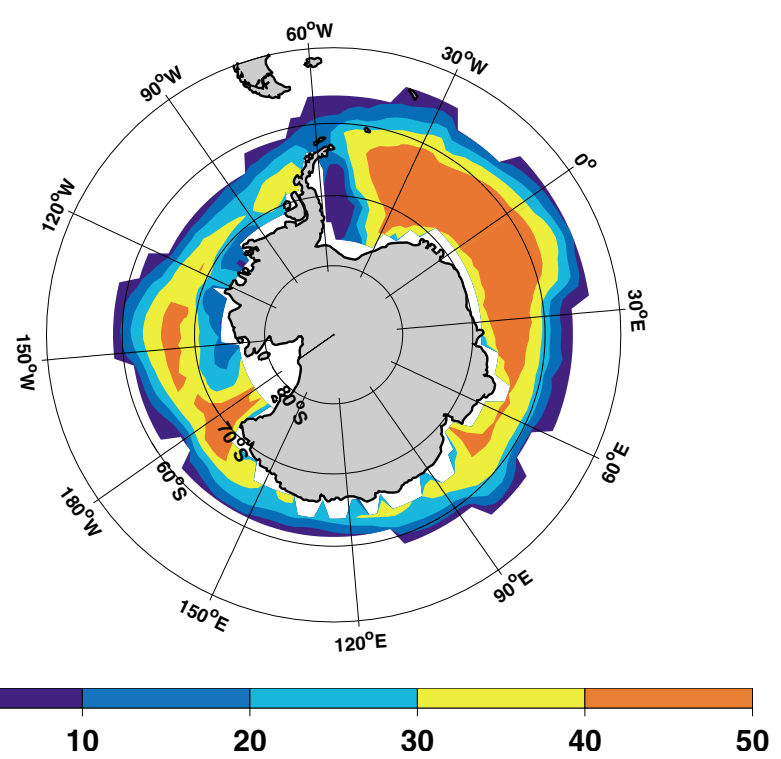

(c)
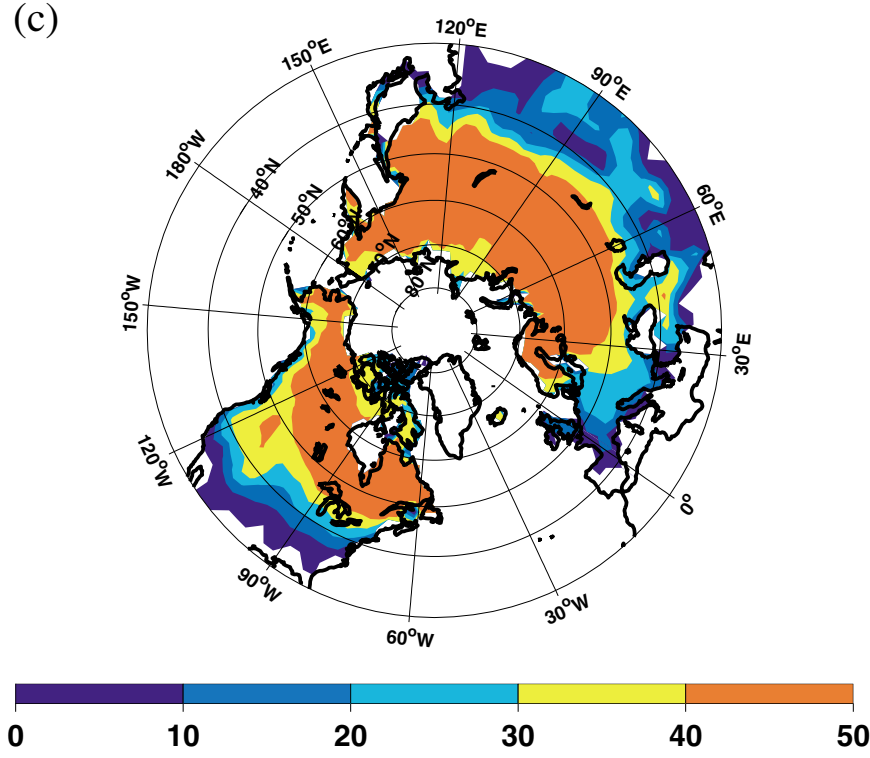

Fig. 3 The spatial distribution of standard deviation of monthly concentrations of the (a) NH sea ice, (b) SH sea ice, and (c) NH land snow. The estimate at each grid box is based on the time series 64 months long (November 1984-February 1990) equatorward of the polar circles, and 52 months long poleward of the polar circles when the data from the NOAA-9 and/or NOAA-10 satellites are available (February 1985-May 1989).

Weddell and Ross seas, with perennial sea ice, and the lower latitude areas where sea ice or land snow appear infrequently.

\section{Conclusions and discussion}

Using more than five years of ERBE all-sky TOA albedo monthly data from the $2.5^{\circ} \times 2.5^{\circ}$ grid over the polar oceans and $\mathrm{NH}$ land, we found that when sea-ice or land-snow cover varies from $0 \%$ to $100 \%$, the TOA albedo changes by about 0.2 with small seasonal changes.

This value is robust across all areas with high ice/snow cover seasonal variability. Over the open ocean and snowfree land, the TOA albedo values are much higher than the surface albedo range caused by the solar zenith angle variations. Over the $100 \%$ ice/snow concentrations, the TOA albedo lies within the surface albedo range caused by the changes in the ice/snow properties and/or the presence of vegetation over land. At the same time, over the areas with perennial sea ice, where SICs are correlated with the TOA albedo, the range of the TOA albedo is small but robust as it is over the peripheral seas while, in general, the SIC varies between $80 \%$ and $100 \%$. This results in very high $R E$ values, however, the changes in the TOA albedo are likely due to the changes in the sea-ice properties and cloud variations rather than SIC changes. 
(a)

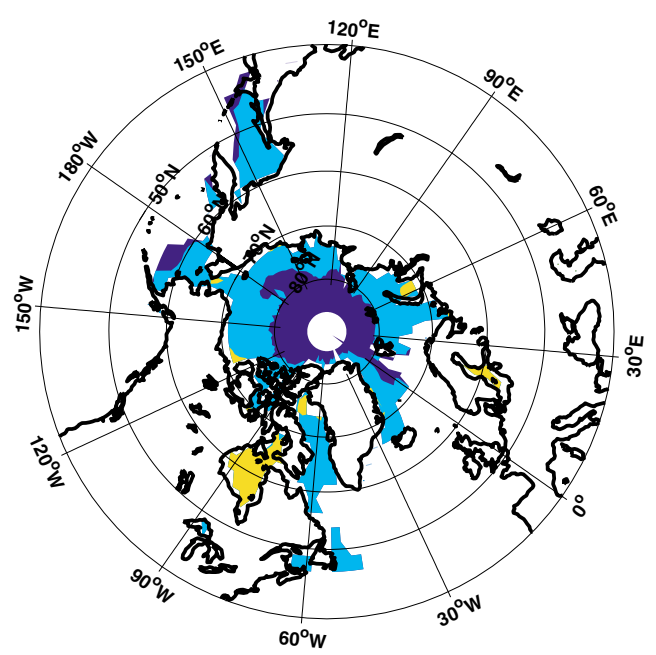

(b)

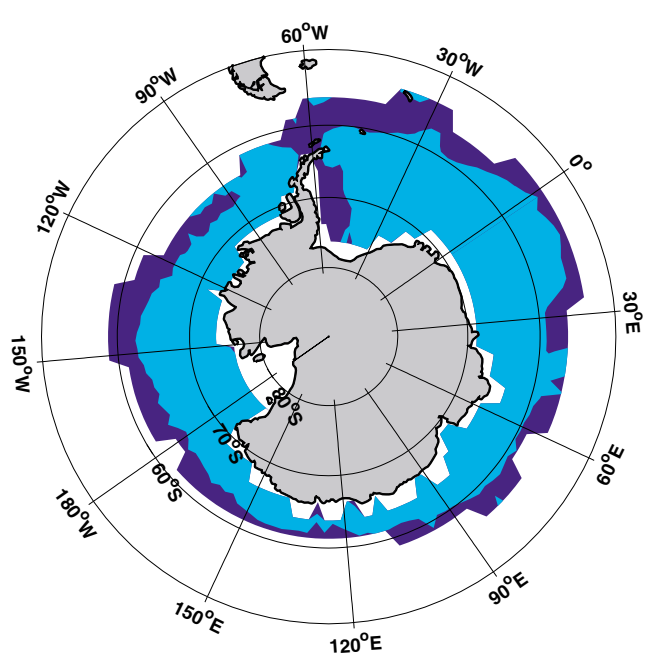

0 0.05
0.1
0.150

(c)

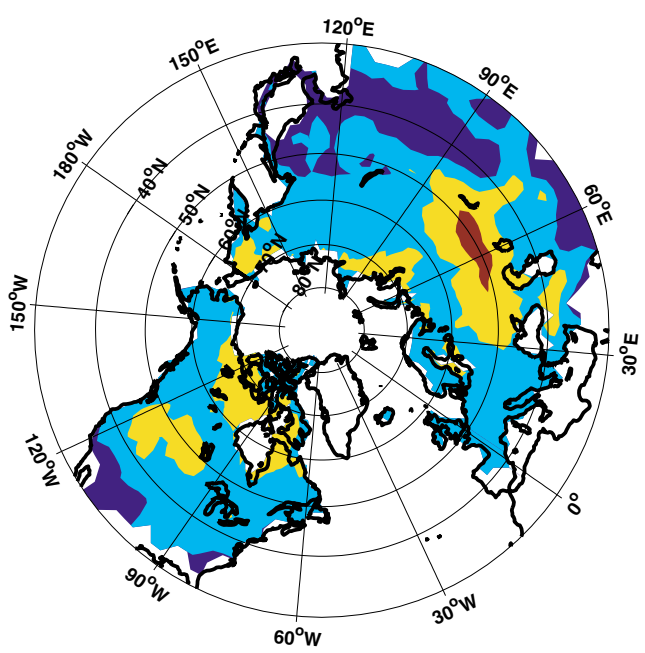

0.05

0.1

0.15

Fig. 4 The spatial distribution of monthly TOA albedo standard deviation for the area of maximum extent of the a) NH sea ice, (b) SH sea ice, and (c) NH land snow. The estimate at each grid box is based on time series 64 months long (November 1984-February 1990) equatorward of the polar circles, and at least 30 months long poleward of the polar circles for only the sunlit grid boxes up to 52 months long when the the data from the NOAA-9 and/or NOAA-10 satellites are available (February 1985-May 1989). The maximum extent of the ice/snow cover includes the grid boxes where ice/snow concentrations were non-zero during at least one month of these time periods.

In general, our estimates of $R E$ necessarily assume the covariability (or anti-covariability) of all TOA albedo-influencing factors with surface conditions as actually occurred during the period of our analysis. For example, positive or negative de-facto correlation in the cloud cover with the ice or snow cover results in a respective increase or decrease in our TOA albedo $R E$ estimate. A similar, although more subtle, mechanism is a possible correlation between the percentage of snow cover and the surface albedo of the snow-free land: positive correlations increase the $R E$ of snow cover, and negative correlations decrease it.
The presence of a high amount of cloud during the whole year in the polar regions shields the effects of the surface on the reflected SW radiative fluxes at the TOA (cf. Ingram et al., 1989; YC97). If the sea-ice retreat in response to the surface warming is associated with increased cloudiness, the latter would reduce the effect of the ice-albedo feedback and its ability to amplify surface warming. However, during seasons when the amount of incoming solar radiation at the TOA is high, the estimated 0.2 radiative effectiveness of ice and snow is enough to influence the reflected SW radiation. In summer, there is more than $400 \mathrm{~W} \mathrm{~m}^{-2}$ of SW radiation incoming to 


\section{4 / Irina V. Gorodetskaya et al.}

the polar latitudes. Local reduction of SICs from $100 \%$ to $0 \%$ would then result in a decrease of about $80 \mathrm{~W} \mathrm{~m}^{-2}$ in reflected (and thus increase in absorbed) SW radiation. The observed negative trends in the Arctic sea-ice extent during 1978-96 (Parkinson et al., 1999; Serreze et al., 2000) have been largest in summer and early autumn in many areas where the correlations between the SIC and TOA albedo anomalies are high (e.g., Arctic peripheral seas). This implies that the increase in absorbed radiation has a substantial impact on the local SW radiation balance.

These estimates of the TOA albedo response to sea-ice and land-snow cover percentage changes provide a useful constraint to test current climate models. Simplified models (e.g., Gildor and Tziperman (2000) who use constant albedo for the atmosphere) should calibrate the ice/snow-albedo feedback, using the $\sim 0.2$ value of TOA $R E$ of sea-ice and land-snow cover, rather than larger values based on surface albedo changes. These estimates can also be useful for evaluation of GCMs used for long-term climate change studies as they differ significantly in simulating both the sea-ice cover and cloud variation in the polar regions (Holland and Bitz, 2003; Zhang et al., 2005). The question is whether the model clouds modify the ice/snow-albedo feedback as much as actual clouds do. Cloud variations and their radiative forcing in the polar regions still remain uncertain.

This study examined the total-sky estimates of the ice/snow effects on the TOA albedo using monthly data from the ERBE program. We extended the few earlier studies of broadband TOA albedo, which either treated only snow or were limited to smaller regions or shorter periods (Groisman et al., 1994; YC97). Understanding the physics behind the $R E$ values found here will require a combination of large-scale (satellite) data analysis, more detailed but spatially and temporally limited ground-based observations, and modelling studies resolving clouds. The new data are currently becoming available from the NASA Earth Observing System where the radiation and atmospheric properties are derived using improved algorithms (Wielicki et al., 1995, 1996). Much improved surface and cloud scene identification over ice/snow surfaces (Kato and Loeb, 2005) will help to separate the effects of ice, snow, and clouds on the radiative fluxes, and to assess the ability of clouds to modify the ice/snow-albedo feedback.

\section{Acknowledgements}

The authors are grateful to Hezi Gildor, Beate Liepert, Cecilia Bitz, Bill Rossow, Pavel Groisman and Judah Cohen for valuable comments and discussions; Seiji Kato, Norman Loeb, Bruce Wielicki and Yuanchong Zhang for information about ERBE data; Nick Rayner for advice on sea-ice data; Richard Ianuzzi, Gerd Krahmann and Felix Tubiana for programming assistance; Katie Leonard for proofreading of the manuscript. We are grateful to Alex Hall and two anonymous reviewers for their comments and suggestions that resulted in significant improvement to the manuscript. We thank NASA's ERBE Data Management Team, the NSIDC, and the Hadley Centre for Climate Prediction and Research for providing satellite data. IG was supported by NOAA grant NA06GP0567, NSF grant ATM-9986515, and NASA Fellowship ESSF0400000163. MAC was supported by NOAA grants NA06GP0567 and NA86GP0437, AK by NSF grant ATM-0233651, LBT by NSF grants OPP-0230264 and OPP-0230325. This is LDEO contribution number 6856.

\section{References}

ALLISON, I.; R. E. BRANDT and S. G. WARREN. 1993. East Antarctic sea ice: albedo, thickness distribution, and snow cover. J. Geophys. Res. 98: 12,417-12,429.

ARMSTRONG, R. L. and M. J. BRODZIK. 2001. Recent Northern Hemisphere snow extent: A comparison of data derived from visible and microwave satellite sensors. Geophys. Res. Lett. 28: 3673-3676.

BARKSTROM, B. R. and G. L. SMITH. 1986. The Earth Radiation Budget Experiment: Science and implementation. Rev. Geophys. 24: 379-390.

— ; E. HARRISON, G. SMITH, R. GREEN, J. KIBLER, R. CESS, and THE ERBE SCIENCE TEAM. 1989. Earth Radiation Budget Experiment (ERBE) archival and April 1985 results. Bull. Am. Meteorol. Soc. 70: 1254-1262.

BUDYKO, M.I. 1969. The effects of solar radiation on the climate of the earth. Tellus, 21: 611-619.

CROLL, J. 1875. Climate and time in their geological relations: A theory of secular changes of the Earth's climate. Appleton, New York, 577 pp.

CURRY, J. A.; J. L. SCHRAMM and E. E. EBERT. 1995. Sea ice-albedo climate feedback mechanism. J. Clim. 8: 240-247.

- ; w. B. ROSSOW, D. RANDALL and J. L. SCHRAMM. 1996. Overview of Arctic cloud and radiation characteristics. J. Clim. 9: 1731-1762.

- and P. J. WEBSTER. 1999. Thermodynamics of atmospheres and oceans. International geophysics series, Vol. 65, Academic Press, London, 471 pp.

— ; J. L. SCHRAMM, D. K. PEROVICH and J. O. PINTO. 2001. Applications of SHEBA/FIRE data to evaluation of snow/ice albedo parameterizations. $J$. Geophys. Res. 106: 15,345-15,355.

DUVEL, J. P.; S. BOUFFIES-CLOCHE and M. VIOLLIER. 2000. Determination of short-wave earth reflectances from visible radiance measurements: error estimate using ScaRaB data. J. Clim. Appl. Meteorol. 39: 957-970.
GILDOR, H. and E. TZIPERMAN. 2000. Sea ice as the glacial cycles' climate switch: Role of seasonal and orbital forcing. Paleoceanogr. 15: $605-615$

GLOERSEN, P.; W. J. CAMPBELl, D. J. CAVALIERI, J. C. COMISO, C. L. PARKINSON and H. J. ZWALLY. 1992. Arctic and Antarctic sea ice, 1978-1987: Satellite passive microwave observations and analysis. NASA SP-511, $290 \mathrm{pp}$.

GROISMAN, P. YA.; T. R. KARL, R. W. KNIGHT and G. L. STENCHIKOV. 1994. Changes of snow cover, temperatures, and radiative heat balance over the Northern Hemisphere. J. Clim. 7: 1633-1656.

HALL, A. 2004. The role of surface albedo feedback in climate. J. Clim. 17: $1550-1568$.

HOLLAND, M. M. and C. M. BITZ. 2003. Polar amplification of climate change in coupled models. Clim. Dyn. 21: 221-232.

INGRAM W. J.; C. A. WILSON and J. F. B. MITCHELL. 1989. Modeling climate change: an assessment of sea ice and surface albedo feedbacks. $J$. Geophys. Res. 94: 8609-8622.

IPCC. 2001. Climate Change: The Scientific Basis. Contribution of Working Group I to the Third Assessment Report of the Intergovernmental Panel on Climate Change J. T. Houghton, Y. Ding, D. J. Griggs, M. Noguer, P. J. van der Linden, X. Dai, K. Maskell and C. A. Johnson (Eds). Cambridge University Press, Cambridge, United Kingdom and New York, NY, USA, 881 pp.

KATO, S. and N. LOEB. 2005. Top-of-atmosphere shortwave broadband observed radiance and estimated irradiance over polar regions from Clouds and the Earth's Radiant Energy System (CERES) instruments on Terra. J. Geophys. Res. 110: doi: 10.1029/2004JD005308. 


\section{Ice and Snow Effects on Planetary Albedo / 205}

KHODRI, M.; M. A. CANE, G. KUKLA and P. BRACONNOT. 2005. The impact of precession changes on the Arctic climate during the last interglacial-glacial transition. Earth Planet. Sci. Lett. 236: 285-304.

KLEIN, S. A. and D. L. HARTMANN. 1993. The seasonal cycle of low stratiform clouds. J. Clim. 6: 1587-1606.

KUANG, Z. and Y. L. YUNG. 2000. Observed albedo decrease related to the spring snow retreat. Geophys. Res. Lett. 27: 1299-1302.

KUKLA, G. and J. GAVIN. 2003. Milankovitch climate reinforcements. Glob. Planet. Change. 40: 27-48.

LI, Z. 1996. On the angular correction of satellite radiation measurements: The perfomance of ERBE angular dependence model in the Arctic. Theor. Appl. Climatol. 54: 235-248.

- and H. G. LEIGHTON. 1991. Scene identification and its effect on cloud radiative forcing in the Arctic. J. Geophys. Res. 96: 9175-9188.

LIOU, K. N. 1992. Radiation and cloud processes in the atmosphere. Theory, observation and modeling. Oxford Monographs on Geology and Geophysics No. 30, Oxford University Press, New York 487 pp.

LUBIN, D.; S. LYNCH, R. CLARKE, E. MORROW and S. HART. 2003. Increasing reflectivity of the Antarctic ocean-atmosphere system: Analysis of Total Ozone Mapping Spectrometer (TOMS) and passive microwave data for 1979-1994. J. Geophys. Res. 108: doi:10.1029/2002JD002702.

MATSON, M. and D. R. WIESNET. 1981. New data base for climate studies. Nature, 289: 451-456.

MILANKOVITCH, M. 1941. Kanon der Erdbestranhlung und seine Anwendung auf das Eiszeitenproblem. Academie Royale Serbe, Edition Speciales, Tome CXXXIII, Section des Sciences Mathematiques et Naturelles, Tome 33. Stampraija Mihaila Curcica -Beograd. (Translated from German: Canon of insolation and the ice-age problem. Israel Program for Scientific Translations, Jerusalem, 1969).

OELKE, C. 1997. Atmospheric signatures in sea-ice concentration estimates from passive microwaves: modelled and observed. Int. J. Remote Sens. 18 : 1113-1136.

PAILLARD, D. 2001. Glacial cycles: toward a new paradigm. Rev. Geophys. 39: 325-346.

PARKINSON, C. L.: D. J. CAVALIERI, P. GLOERSEN, H. J. ZWALLY and J. C. COMISO. 1999. Arctic sea ice extents, areas, and trends, 1978-1996. J. Geophys. Res. 104: 20,837-20,856.

QU, X. and A. HALL. 2005. Surface contribution to planetary albedo variability in cryosphere regions. J. Clim. 18: 5239-5252.

RAYNER N. A.; D. E. PARKER, E. B. HORTON, C. K. FOLLAND, L. V. ALEXANDER, D. P. ROWELL, E. C. KENT and A. KAPLAN. 2003. Global analyses of sea surface temperature, sea ice, and night marine air temperature since the late nineteenth century. J. Geophys. Res. 108: No. D14, 4407, doi:10.1029/2002 JD002670.

RIELAND, M. and E. RASCHKE. 1991. Diurnal variability of the Earth radiation budget: Sampling requirements, time integration aspects and error estimates for the Earth Radiation Budget Experiment (ERBE). Theor. Appl. Climatol. 44: 9-24.
ROBINSON, D. A. and G. KUKLA. 1985. Maximum surface albedo of seasonally snow-covered lands in the Northern Hemisphere. J. Clim. Appl. Meteorol. 24: 402-411.

- K. F. DEWEY and R. R. HEIM, JR. 1993. Global snow cover monitoring: An update. Bull. Am. Meteorol. Soc. 74: 1689-1696.

SCIALDONE, J. and A. ROBOCK. 1987. Comparison of Northern Hemisphere snow cover data sets. J. Clim. Appl. Meteorol. 26: 53-68.

SELLERS, W. D. 1969. A global climatic model based on the energy balance of the Earth-atmosphere system. J. Appl. Meteorol. 8: 392-400.

SERREZE, M. C.; J. E. BOX, R. G. BARRY and J. E. WALSH. 1993. Characteristics of Arctic synoptic activity, 1952-1989. Meteorol. Atmos. Phys. 51: $147-164$.

- ; J. E. WALSH, F. S. CHAPIN III, T. OSTERKAMP, M. DYURGEROV, V. ROMANOVSKY, W. C. OECHEL, J. MORISON, T. ZHANG and R. G. BARRY. 2000. Observational evidence of recent change in the northern high-latitude environment. Climatic Change, 46: 159-207.

- ; A. H. LYNCH and M. P. CLARK. 2001. The Arctic frontal zone as seen in the NCEP-NCAR reanalysis. J. Clim. 14: 1550-1567.

SMITH, G. L. and N. MANALO-SMITH. 1995. Scene identification error probabilities for evaluating Earth radiation measurements. J. Geophys. Res. 100: $16,377-16,385$.

WANG, Z.; R. -M. HU, L. A. MYSAK, J. -P. BLANCHET and J. FENG. 2004. A parametrization of solar energy disposition in the climate system. ATMOSPHEREOCEAN, 42: 113-125.

WIELICKI, B. A. and R. N. GREEN. 1989. Cloud identification for ERBE radiative flux retrieval. J. Appl. Meteorol. 28: 1133-1146.

- ; R. D. CESS, M. D. KING, D. A. RANDALL and E. F. HARRISON. 1995. Mission to planet Earth - role of clouds and radiation in climate. Bull. Am. Meteorol. Soc., 76: 2125-2153.

- ; B. R. BARKSTROM, E. F. HARRISON, B. B. LEE III, G. LOUIS SMITH and J. E. COOPER. 1996. Clouds and the Earth's Radiant Energy System (CERES) an earth observing system experiment. Bull. Am. Meteorol. Soc. 77: $853-868$.

WIESNET, D. R.; C. F. ROPELEWSKI, G. J. KUKLA and D. A. ROBINSON. 1987. A discussion of the accuracy of NOAA satellite-derived global seasonal snow cover measurements. In: Proc. Symp. on Large Scale Effects of Seasonal Snow Cover, B. E. Goodison, R. G. Barry and J. Dozier (Eds), August 1987. Vancouver, BC, Canada, IAHS, pp. 291-304.

YAMANOUCHI, T. and T. P. CHARLOCK. 1997. Effects of clouds, ice sheet, and sea ice on the Earth radiation budget in the Antarctic. J. Geophys. Res. 102: 6953-6970.

ZHANG, M. H.; W. Y. LIN, S. A. KLEIN, J. T. BACMEISTER, S. BONY, R. T. CEDERWALL, A. DELGENIO, J. J. HACK, N. G. LOEB, U. LOHMANN, D. MINNIS, I. MUSAT, R. PINCUS, P. STIER, M. J. SUAREZ, M. J. WEBB, J. B. WU, S. C. XIE, M. S. YAO and J. H. ZHANG. 2005. Comparing clouds and their seasonal variations in 10 atmospheric general circulation models with satellite measurements. J. Geophys. Res. 110: D15S02, doi:10.1029/2004JD005021. 